\section{Transcriptional repression by PRC1 in the absence of $\mathrm{H} 2 \mathrm{~A}$ monoubiquitylation}

\author{
Ana Raquel Pengelly, Reinhard Kalb, Katja Finkl, \\ and Jürg Müller
}

\begin{abstract}
Laboratory of Chromatin Biology, Max Planck Institute of Biochemistry, 82152 Martinsried, Germany
\end{abstract}

Histone H2A monoubiquitylation (H2Aub) is considered
to be a key effector in transcriptional repression by Poly-
comb-repressive complex 1 (PRC1). We analyzed Droso-
phila with a point mutation in the PRC1 subunit Sce
that abolishes its H2A ubiquitylase activity or with point
mutations in the H2A and H2Av residues ubiquitylated
by PRC1. H2Aub is essential for viability and required
for efficient histone H3 Lys27 trimethylation by PRC2
early in embryogenesis. However, H2Aub-deficient ani-
mals fully maintain repression of PRC1 target genes and
do not show phenotypes characteristic of Polycomb group
mutants. PRC1 thus represses canonical target genes in-
dependently of H2Aub. Supplemental material is available for this article.

Received May 11, 2015; revised version accepted June 24, 2015.

Polycomb (Pc) group (PcG) proteins form conserved multiprotein complexes that repress transcription of developmental regulator genes in cells where they should be inactive (Beisel and Paro 2011; Simon and Kingston 2013). PcG protein complexes are thought to silence gene transcription through covalent and noncovalent modification of chromatin at target genes. Polycomb-repressive complex 2 (PRC2) trimethylates Lys27 in histone $\mathrm{H3}$ (H3-K27me3), and, in Drosophila, cells with an $H 3^{K 27 R}$ point mutation fail to repress PcG target genes, demonstrating the importance of this modification for repression (Pengelly et al. 2013; McKay et al. 2015). The H3-K27me3 modification is recognized by Pc, a subunit of PRC1, and thus is thought to mark nucleosomes for interaction with PRC1 (Fischle et al. 2003; Min et al. 2003). PRC1 compacts nucleosome arrays in vitro by a nonenzymatic mechanism (Shao et al. 1999; Francis et al. 2004), and domains of PRC1 subunits important for this activity are critical for gene repression in vivo (King et al. 2005; Isono et al. 2013; Gambetta and Müller 2014).

PRC1 also contains the E3 ligase activity for monoubiquitylation of H2A at Lys119 in mammals or at the corresponding Lys118 in Drosophila (Wang et al. 2004; Lagarou et al. 2008). The mechanism and physiological role of monoubiquitylated histone $\mathrm{H} 2 \mathrm{~A}$ (H2Aub) is poorly understood. Early studies proposed that H2Aub directly blocks

[Keywords: Polycomb; PRC1; H2A and H2Av monoubiquitylation; transcriptional repression; Drosophila]

Corresponding author: muellerj@biochem.mpg.de

Article published online ahead of print. Article and publication date are online at http://www.genesdev.org/cgi/doi/10.1101/gad.265439.115. transcription elongation by RNA polymerase II (Stock et al. 2007). More recent studies found that H2Aub is bound by a specific form of PRC2 and promotes H3$\mathrm{K} 27 \mathrm{me} 3$ by this complex on $\mathrm{H} 2 \mathrm{Aub}$ nucleosomes in vitro (Kalb et al. 2014). In mouse embryonic stem (ES) cells, tethering of PRC1 E3 ligase activity to a chromosomal site was found to result in $\mathrm{H} 2 \mathrm{~A}$ monoubiquitylation, binding of PRC2, and H3-K27me3 formation at this site, leading to the proposal that a primary function of $\mathrm{H} 2 \mathrm{Aub}$ might be to recruit PRC2 (Blackledge et al. 2014).

The E3 ligase activity for H2Aub formation is provided by the PRC1 subunit Ring1b and its paralog, Ringla, in vertebrates and by Sce in Drosophila (de Napoles et al. 2004; Wang et al. 2004). Drosophila lacking Sce protein show loss of H2Aub (Lagarou et al. 2008; Gutiérrez et al. 2012), whereas, in vertebrates, only removal of both Ringla and Ring1b proteins results in complete loss of H2Aub (de Napoles et al. 2004). Sce and Ring1a/b also play an architectural role in PRC1. The N-terminal Ring finger domain of Ringla/b (or Sce) associates with the Ring finger domains of the different PCGF family members (Buchwald et al. 2006; Li et al. 2006) to form the core of the various PRC1-type assemblies (Gao et al. 2012), while the $\mathrm{C}$ terminus binds to the $\mathrm{Cbx} / \mathrm{Pc}$ or Rybp subunits (Schoorlemmer et al. 1997; Wang et al. 2010). The reduced levels of diverse PRC1 subunits in Ring1b mutant mouse ES cells (Leeb and Wutz 2007) supports the idea that Ring $1 \mathrm{a} / \mathrm{b}$ is critical for integrity of PRC1 assemblies. In turn, this raises the question of to what extent the severe phenotypes of mouse embryos lacking Ring1b protein (Voncken et al. 2003) or Drosophila lacking Sce protein (Gutiérrez et al. 2012) can be attributed to the loss of $\mathrm{H} 2 \mathrm{Aub}$.

Selective impairment of E3 ligase activity in an otherwise intact Ring1b protein can be achieved by the I53A substitution in the interface that binds the E2 ubiquitinconjugating enzyme (Buchwald et al. 2006; Bentley et al. 2011). Previous studies used transgenes expressing the Ring $1 b^{\mathrm{I} 53 \mathrm{~A}}$ protein to manipulate H2Aub levels in mouse ES cells lacking Ring1b (Eskeland et al. 2010) or Ringla and Ring1b (Endoh et al. 2012). Endoh et al. (2012) reported that $\mathrm{H} 2 \mathrm{Aub}$ was required for maintenance of ES cell identity and efficient repression of a distinct subset of PcG target genes.

Here, we investigated the role of $\mathrm{H} 2 \mathrm{Aub}$ in developing Drosophila. We generated animals in which we replaced wild-type Sce with a catalytically inactive Sce protein and, in parallel, animals in which we mutated the residues in $\mathrm{H} 2 \mathrm{~A}$ and its variant, $\mathrm{H} 2 \mathrm{Av}$, that are monoubiquitylated by PRC1. We show that $\mathrm{H} 2 \mathrm{Aub}$ is not required for repression of canonical PcG target genes and that H2Aub-deficient animals arrest development with surprisingly mild morphological defects. Together, these results suggest that PRC1 represses target genes primarily through an H2Aub-independent mechanism. 


\section{Results and Discussion}

Sce E3 ligase activity for H2Aub formation is not required for repression of canonical PRC1 target genes

In a first approach, we analyzed Drosophila lacking Sce E3 ligase activity. In an initial set of experiments, we generated $S c e^{K O} m_{-z-}$ mutant embryos that were homozygous for Sce ${ }^{K O}$ (a small chromosomal deletion that removes the entire Sce ORF) (Gutiérrez et al. 2012) and lacked not only zygotically expressed $(z-)$ but also maternally deposited $(m-)$ wild-type Sce protein (Fig. 1A, panel 1, cf. lanes 4-6 and 1-3; see Supplemental Fig. S1 for experimental strategy). Using an antibody that specifically detects H2Aub, we found that $\mathrm{H} 2 \mathrm{Aub}$ was undetectable in $\mathrm{Sc} e^{\mathrm{KO} \mathrm{m}_{-\mathrm{z}-}} \mathrm{mu}-$ tant embryos but readily detected in wild-type embryos (Fig. 1A, panel 9, cf. lanes 4-6 and 1-3), demonstrating that Sce is responsible for all monoubiquitylation of H2A at Lys118. In Sce ${ }^{K O} \mathrm{~m}_{-z-}$ embryos, bulk levels of the PRC1 subunits Ph-p, Ph-d, Scm, and Psc; the PhoRC subunit Pho; the PRC2 subunit E(z); or Ogt were comparable with wild type (Fig. 1, panels 3-8; cf. Gutiérrez et al. 2012). However, bulk levels of the PRC1 subunit Pc were about threefold reduced in $S c e^{K O} m_{-z-}$ embryos compared with wild-type embryos (Fig. 1, panel 2, cf. lanes 4-6 and 1-3). This observation parallels the finding that bulk levels of the Pc ortholog Cbx4 are strongly reduced in Ring1b mutant mouse ES cells (Leeb and Wutz 2007) and evidently limits the interpretation of to what extent the $S c e^{K O m_{-z-}}$ mutant phenotype (Fig. 1B, middle panels) can be attributed to the lack of H2Aub.

In the next set of experiments, we therefore generated animals that contain a Sce ${ }^{\mathrm{I} 48 \mathrm{~A}}$ mutant protein instead of wildtype Sce. The I48A mutation in Sce corresponds to the I53A mutation in Ring1b that impedes its E3 ligase activity for H2Aub (see above). We first generated Sce $e^{148 \mathrm{Am}-\mathrm{z}-}$ mutant embryos in which both zygotically expressed and maternally deposited Sce protein contained the I48A mutation; the Sce ${ }^{\mathrm{I} 48 \mathrm{~A}}$ protein was expressed at normal levels from a genomic Sce fragment (Fig. 1A, panel 1, cf. lanes 7-9 and 1-3; see Supplemental Fig. S1 for experimental strategy). In Sce $e^{I 48 A} A_{-z-}$ mutant animals, all analyzed PcG proteins, including Pc, were present at wild-type levels (Fig. 1A, panels 2-8), but H2Aub was still $>98 \%$ reduced (Fig. 1A, panel 9, cf. lanes 7-9 and 1-3). These Sce $e^{I 48 A ~ m-z-}$ mutant embryos thus allowed us to selectively assess the requirement for $\mathrm{H} 2 \mathrm{Aub}$ in Drosophila.

We first investigated how loss of H2Aub affects H3$\mathrm{K} 27 \mathrm{me} 3$ by PRC2. H3-K27me3 bulk levels in Sce $e^{I 48 A} \mathrm{m-z-}$ and $S c e^{K O ~} \mathrm{~m}_{-z-}$ mutant embryos were $\sim 1.5$-fold lower than in wild-type embryos (Fig. 1A, panel 10; Supplemental Fig. S2; discussed below).

We next compared the phenotype of $S c e^{I 48 A \mathrm{~m}-z-}$ mutant embryos with that of $S c e^{K O}{ }_{m-z-}$ mutant embryos. The embryonic cuticle of Sce $e^{K O} \mathrm{m-z-}$ mutant embryos shows extensive homeotic transformations (Fig. 1B) caused by widespread misexpression of $H O X$ genes such as Antennapedia (Antp), Ultrabithorax $(U b x)$, and $A b$ -

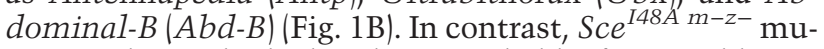
tant embryos looked indistinguishable from wild-type embryos: They did not show any detectable homeotic transformations or any other defects in the embryonic cuticle, and expression of $A n t p, U b x$, and $A b d-B$ was confined to their normal expression domains (Fig. 1B). Moreover, engrailed (en), another classic PcG target gene that is misexpressed in $S c e^{K O} m_{-z-}$ mutant embryos (Fig. 1B),
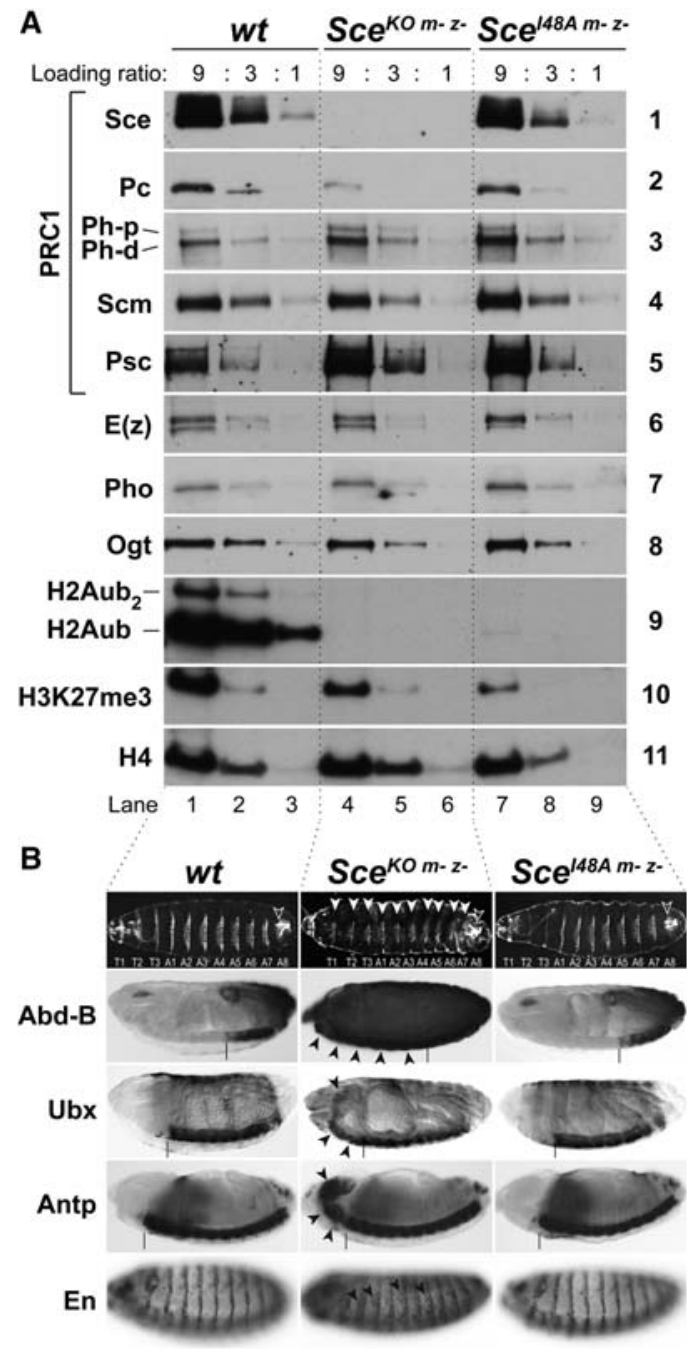

Figure 1. Embryos lacking $\mathrm{H} 2 \mathrm{Aub}$ maintain repression of PcG target genes. (A) Western blot analysis on serial dilutions (9:3:1) of soluble nuclear extracts (panels 1-8) and chromatin extracts (panels 9-11) from the same batch of 0 - to 12 -h-old wild-type, Sce $\mathrm{KO}_{\mathrm{m-z}}$, or $S c e^{I 48 A} \mathrm{~m}_{-2-}$ embryos. An independent experiment of the histone modification analysis is documented in Supplemental Figure S2. (B) Ventral views of embryonic cuticles (top row) and side views of stage 14-16 embryos (second through fifth rows) stained with the indicated antibodies. (Top row) Wild-type embryos show characteristic denticle belts in thoracic (T1-T3) and abdominal (A1-A8) segments; in $S c e^{K O} \mathrm{m-z-}$ animals, T1-A7 are transformed (arrowheads) into copies resembling A8 (empty arrowhead). Cuticles from Sce $e^{I 48 A}$ m-zanimals are indistinguishable from wild type. (Second through fourth rows) In Sce ${ }^{K O} \mathrm{m-z}_{-}$embryos, Abd-B, Ubx, and Antp are each misexpressed (arrowheads) anterior to the boundary of their wildtype expression domain (marked by a vertical bar in each case); in $S c e^{I 48 A} \mathrm{~m}-z-$ animals, no misexpression is detected. (Bottom row) In wild-type and Sce $e^{I 48 A} \mathrm{m-z-}$ animals, En expression is confined to the posterior compartment of every segment, while, in $S c e^{K O m-z-}$ animals, En is misexpressed in anterior compartment cells (arrowheads). $n>50$ in all cases; $100 \%$ penetrance.

also showed a wild-type expression pattern in $S c e^{I 48 A ~ m-z-}$ mutant embryos (Fig. 1B). Polycomb repression of the $H O X$ and en genes is thus unaffected in embryos lacking $\mathrm{H} 2 \mathrm{Aub}$.

Even though Sce $e^{I 48 \mathrm{~A} \mathrm{m-z-}}$ mutant animals showed overall normal morphology (Fig. 1B), they nevertheless 
arrested development at the end of embryogenesis. To explore whether morphogenesis or tissue patterning might be affected in more subtle ways, we stained late stage Sce $e^{I 48 \mathrm{~A} m-z-}$ mutant embryos with anti-Futsch (22C10) antibody to visualize the cells of the peripheral nervous system (PNS) or with anti-myosin heavy chain (Mhc) antibody to visualize muscle cells. Development and patterning of PNS and muscle tissues in Sce $e^{I 48 \mathrm{~A} \mathrm{m-z-}}$ mutant embryos was comparable with that of wild-type embryos (Supplemental Fig. S3). However, Sce $e^{I 48 \mathrm{~A} \mathrm{m-z-}}$ mutant animals occasionally showed aberrant neuronal or muscle fiber connections (Supplemental Fig. S3). These defects were detected in only a fraction of the Sce $e^{I 48 A \mathrm{~m}-\mathrm{z}-} \mathrm{mu}-$ tant embryos and occurred in random locations rather than a stereotype pattern in the body, making it difficult to quantify the defects. Together, these data suggest that overall cell type specification and patterning of epidermal, mesodermal, and PNS tissues occurs normally in embryos lacking H2Aub but that random cells or small groups of cells display morphogenetic defects.

\section{Post-embryonic development, metamorphosis, and differentiation in the absence of $\mathrm{H} 2 \mathrm{Aub}$}

We next generated $S c e^{I 48 A}$ z- mutant animals that expressed Sce ${ }^{\mathrm{I} 48 \mathrm{~A}}$ mutant protein from their zygotic genome but contained a supply of maternally deposited wild-type Sce protein during the early stages of embryogenesis. To investigate perdurance of maternally deposited Sce protein, we analyzed extracts from $S c e^{K O}{ }^{z-}$ mutant embryos (i.e., lacking zygotic expression of Sce) and found that residual maternally supplied wild-type Sce protein and $\mathrm{H} 2 \mathrm{Aub}$ generated by this protein are present in late stage embryos (Supplemental Fig. S4A). Sce $e^{I 48 A z-}$ mutant animals developed beyond the end of embryogenesis, completed all stages of larval development, and formed pupae, and a small fraction developed into pharate adults (Supplemental Fig. S4B). As expected, because of dilution of maternally deposited Sce and H2Aub by cell division and turnover during larval growth, H2Aub was no longer detectable in $S c e^{I 48 \mathrm{~A} z-}$ mutant third instar larvae (Fig. 2A). Of note, bulk levels of $\mathrm{H} 3-\mathrm{K} 27 \mathrm{me} 3$ in these animals were comparable with those in wild-type larvae (Fig. 2A; discussed below). The exoskeleton of Sce $e^{I 48 A}{ }^{z-}$ pharate adults showed all of the features of wild-type Drosophila (Fig. 2B) with variable morphological defects (see below). However, these animals showed no homeotic transformations in head, thoracic, or abdominal segments, whereas such transformations were readily observed in clones of Sce ${ }^{K O}$ mutant cells (Fig. 2B,C). Because the majority of $S c e^{I 48 A z-}$ mutants arrested development as late pupae without forming an adult exoskeleton (Supplemental Fig. S4B), we also analyzed HOX gene expression in these animals. The HOX genes $U b x$ and $A b d-B$ remained fully silenced in imaginal discs of $S c e^{I 48 A} z^{-}$mutant larvae but were widely misexpressed in cell clones lacking Sce protein (Fig. 2C). Taken together, these data suggest that $\mathrm{H} 2 \mathrm{Aub}$ is not required for repression of $H O X$ genes during post-embryonic development.

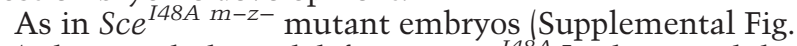
S3), the morphological defects in Sce $e^{I 48 A z^{-}}$pharate adults were variable and showed no consistent pattern (Fig. 2B, cf. the two Sce $e^{I 48 A} z-$ individuals). The most conspicuous and consistent phenotype in these $S c e^{I 48 A z-}$ animals was defective fusion of left and right hemisegments in thoracic

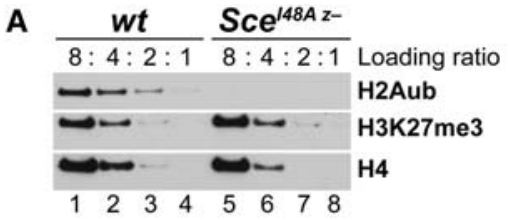

B

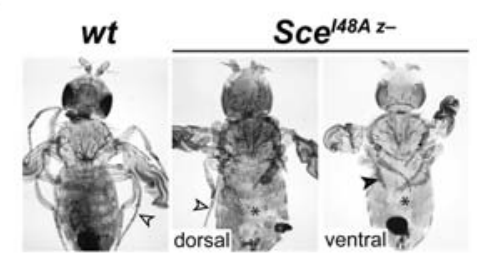

C

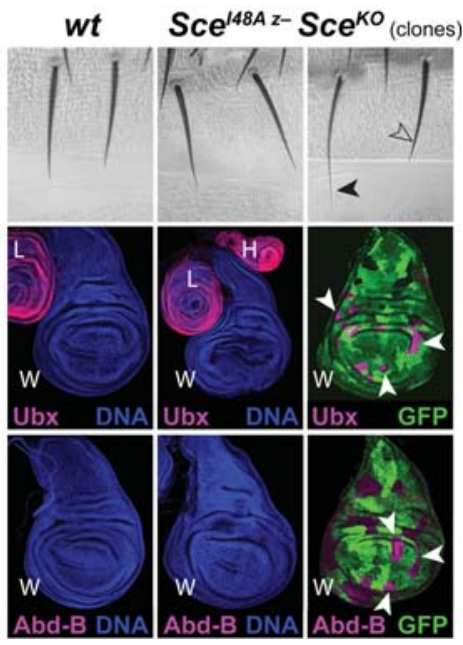

Figure 2. Larval cells lacking H2Aub maintain repression of PcG target genes. $(A)$ Western blot analysis on serial dilutions (8:4:2:1) of histone acid extracts from diploid tissues from wild-type and $S c e^{I 48 A z-}$ mutant third instar larvae. (B) Dorsal view of a freshly hatched (wings not yet inflated) wild-type adult (genotype: $\left.\mathrm{Sce}^{+} ; \mathrm{Sce}^{K O} ; n>100\right)$ and dorsal and ventral views of $S c e^{I 48 A z-}$ pharate adults $(n>30)$. Most body structures in $S c e^{I 48 A} z_{-}$animals appear overall normal, but note the variability in leg morphology, ranging from nearly normal (empty arrowhead) to shortened and malformed (arrowhead); asterisks mark incomplete fusion of left and right hemisegments. See Supplemental Figure. S4B,C. (C, top row) Portions of abdominal segment A2 from a wild-type adult, a $S c e^{I 48 A}$ z- pharate adult, and an adult with clones of $S c e^{K O}$ homozygous cells $(n>20$ dissected abdomens in each case). Bristles in $S c e^{I 8 A A} z-$ animals show wild-type morphology; the bristle formed by $S c e^{K O}$ mutant clone cells (arrowhead), marked by yellow mutation and therefore more lightly pigmented than the bristle formed by wild-type cells in nonclone tissue (empty arrowhead), is elongated and tapered and resembles bristles characteristic of abdominal segment A10 in wild-type animals because of homeotic transformation of the $S c e^{K O}$ mutant tissue. (Middle and bottom rows) Wing $(\mathrm{W})$, haltere $(\mathrm{H})$, and third leg $(\mathrm{L})$ imaginal discs from third instar larvae of the same genotypes as above, stained with antibody against Ubx or Abd-B (magenta). $U b x$ and $A b d-B$ remain repressed in $S c e^{I 48 A z-}$ mutant wing discs (middle) but are misexpressed in clones of $S c e^{K O}$ homozygous cells in this tissue (right; $S c e^{K O}$ cells are GFP-negative). Discs from wild-type and $S c e^{I 48 A z-}$ larvae were costained with Hoechst (blue) to visualize nuclei; normal Ubx expression in haltere and third leg discs served as control. Sce $e^{K O}$ mutant clones were induced 96 h before analysis. $n>20$ in all cases; $100 \%$ penetrance.

and abdominal segments, accompanied by a loss of macrochaete and microchaete in the affected area (Fig. 2B; Supplemental Fig. S4B). 
Cells containing H2A and H2Av that cannot be ubiquitylated maintain repression of PcG target genes

To complement the analysis of mutants lacking Sce E3 ligase activity, we generated animals in which wild-type $\mathrm{H} 2 \mathrm{~A}$ was replaced with a mutant form of $\mathrm{H} 2 \mathrm{~A}$ that cannot be ubiquitylated. On vertebrate nucleosomes, PRC1-type complexes ubiquitylate $\mathrm{H} 2 \mathrm{~A}$ at K119 and K118 but are unable to add ubiquitin to the more C-terminally located K125, K127, or K129 (Wang et al. 2004; Elderkin et al. 2007; McGinty et al. 2014). In Drosophila, the C terminus of H2A contains K117 and K1 18 (which correspond to K118 and K119 in mammals) and two further lysines nearbyK121 and K122 (Supplemental Fig. S5A). In vitro ubiquitylation reactions with the Ring $1 \mathrm{~b} / \mathrm{Bmil}$ Ring finger module of mammalian PRC1 on reconstituted recombinant Drosophila nucleosomes revealed that only mutation of K117, $\mathrm{K} 118$, K121, and K122 completely abolished monoubiquitylation of H2A (Supplemental Fig. S5A). For in vivo investigation of an $\mathrm{H} 2 \mathrm{~A}$ mutant that cannot be ubiquitylated, we therefore used a $\mathrm{H} 2 \mathrm{~A}^{\mathrm{K} 117 \mathrm{R} / \mathrm{K} 118 \mathrm{R} / \mathrm{K} 121 \mathrm{R} / \mathrm{K} 122 \mathrm{R}}$ mutant (referred to below as $\mathrm{H} 2 \mathrm{~A}^{4 \mathrm{~K}>4 \mathrm{R}}$ ). In Drosophila, the canonical histone genes are all located in the histone gene cluster (His $C$ ) that consists of 23 repeats of the histone gene unit comprising the $\mathrm{H} 2 \mathrm{~A}, \mathrm{H} 2 \mathrm{~B}, \mathrm{H} 3, \mathrm{H} 4$, and $\mathrm{H} 1$ genes. Transgene cassettes providing 12 copies of the wild-type histone gene unit rescue animals that are homozygous for a HisC deletion $\left(H i s C^{\Delta}\right)$ into viable adults (Günesdogan et al. 2010). His $C^{\Delta}$ homozygotes that carried the same transgene cassettes with a $\mathrm{H} 2 \mathrm{~A}^{4 \mathrm{~K}>4 \mathrm{R}}$ mutant instead of wildtype $\mathrm{H} 2 \mathrm{~A}$ arrested development at the end of embryogenesis, showing an embryonic cuticle indistinguishable from wild-type embryos (data not shown). We did not investigate the phenotype of these embryos further because their cells still contained maternally deposited wild-type $\mathrm{H} 2 \mathrm{~A}$ that had been only partially replaced by $\mathrm{H} 2 \mathrm{~A}^{4 \mathrm{~K}>4 \mathrm{R}}$ during the few cell divisions that took place between the blastoderm stage and the end of embryogenesis. To analyze cells with a more complete replacement of $\mathrm{H} 2 \mathrm{~A}$ by $\mathrm{H} 2 \mathrm{~A}^{4 \mathrm{~K}>4 \mathrm{R}}$, we used a previously reported strategy (Pengelly et al. 2013) and generated clones of His $C^{\Delta}$ homozygous cells in imaginal discs of His $C^{\Delta}$ heterozygotes carrying the $\mathrm{H} 2 \mathrm{~A}^{4 \mathrm{~K}>4 \mathrm{R}}$ transgene cassette. The $H O X$ genes $U b x$ and $A b d-B$ remained fully silenced in such $\mathrm{H} 2 \mathrm{~A}^{4 \mathrm{~K}>4 \mathrm{R}}$ mutant cell clones (cf. Figs. 3A and 2). Moreover, clones of $\mathrm{H} 2 \mathrm{~A}^{4 \mathrm{~K}>4 \mathrm{R}}$ mutant cells differentiated to form normal epidermal structures in the cuticle of adult flies (cf. Figs. 3B and 2). Repression of $H O X$ genes is thus not impaired in cells in which $\mathrm{H} 2 \mathrm{~A}$ can no longer be ubiquitylated by PRC1.

In a final set of experiments, we explored whether repression of PcG target genes was also maintained in $\mathrm{H} 2 \mathrm{~A}^{4 \mathrm{~K}>4 \mathrm{R}}$
mutant cells in which the histone variant $\mathrm{H} 2 \mathrm{Av}$ could no longer be ubiquitylated. $H 2 A v$, a single-copy gene, encodes the only $\mathrm{H} 2 \mathrm{~A}$ variant in Drosophila and is not located in the His C locus. H2Av contains a lysine pair, K120 and $\mathrm{K} 121$, at the position corresponding to K118/K119 in $\mathrm{H} 2 \mathrm{~A}$ and, in vivo, is also ubiquitylated by Sce (Supplemental Fig. S5B, cf. lanes 1-3 and 7-9|. First, we constructed a Drosophila strain in which the $H 2 A v$ gene was replaced by a $H 2 A V^{K 120 R / K 121 R}$ mutant (referred to below as $\left.H 2 A v^{2 K>2 R}\right)$. The strategy to generate the $H 2 A v^{K O}$-null allele and $H 2 A v^{2 K>2 R}$ mutant animals is presented in Supplemental Figure S6A-D and the Materials and Methods. $H 2 A v^{2 K>2 R}$ mutants were viable and fertile and showed no obvious morphological defects even though the $\mathrm{H} 2 \mathrm{Av}^{2 \mathrm{~K}>2 \mathrm{R}}$ protein in these animals was no longer monou-

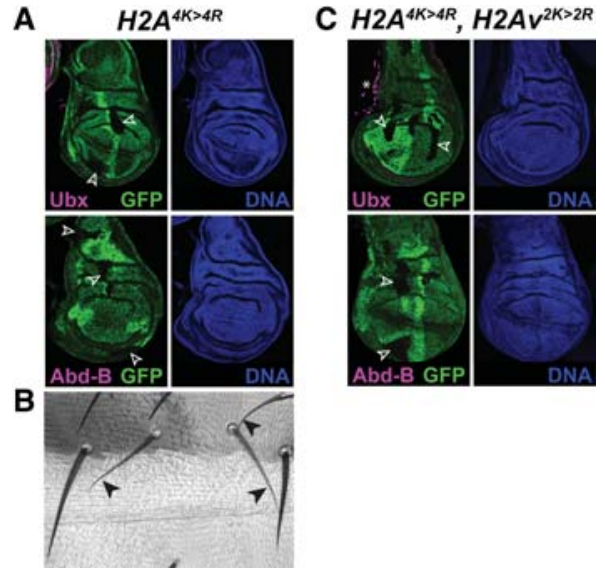

Figure 3. Larval cells containing mutated $\mathrm{H} 2 \mathrm{~A}$ and $\mathrm{H} 2 \mathrm{Av}$ proteins that cannot be ubiquitylated maintain repression of PcG target genes. (A) Imaginal wing discs with clones of $H 2 A^{4 K>4 R}$ mutant cells (GFPnegative), stained with antibodies against Ubx or Abd-B (magenta in both cases); Hoechst staining of corresponding discs is shown in blue. Clones were induced $96 \mathrm{~h}$ before analysis. No misexpression of $U b x$ or $A b d-B$ was detected in mutant clones (empty arrowheads). $n>30$ discs with multiple clones each; $100 \%$ penetrance. $(B)$ Portion of abdominal segment A2 from an adult with a clone of $H 2 A^{4 K>4 R}$ mutant cells, marked with the yellow mutation like in Figure 2C. Bristles formed by $H 2 A^{4 K>4 R}$ mutant clone cells have a wild-type appearance. $n>15$ abdomens with multiple clones each; $100 \%$ penetrance. $(C)$ Imaginal wing discs with clones of $H 2 A^{4 K>4 R}$ and $H 2 A v^{2 K>2 R}$ double-mutant cells stained with Ubx or Abd-B antibodies as in $A$. No misexpression of $U b x$ or $A b d-B$ was detected in the mutant clones (empty arrowheads); the signal marked by an asterisk is normal $U b x$ expression in a trachea attached to the wing disc. $n>20$ discs with multiple clones each; $100 \%$ penetrance.

biquitylated (Supplemental Fig. S5B, cf. lanes 4-6 and 1-3). Monoubiquitylation of $\mathrm{H} 2 \mathrm{Av}$ by $\mathrm{PRC} 1$ is thus dispensable for normal development, viability, and fertility in Drosophila. Next, we generated clones of $H 2 A^{4 K>4 R} H 2 A v^{2 K>2 R}$ mutant cells in imaginal discs (Supplemental Fig. S6E). $U b x$ and $A b d-B$ remained fully silenced in $H 2 A^{4 K>4 R}$ $H 2 A v^{2 K>2 R}$ double-mutant cells (Fig. 3C). Together, these results argue that the ubiquitylation of $\mathrm{H} 2 \mathrm{~A}$ or $\mathrm{H} 2 \mathrm{Av}$ is not critical for PRC1-mediated repression of $H O X$ genes.

\section{Implications for mechanisms of PcG-mediated gene repression and $\mathrm{H} 2 \mathrm{Aub}$ function}

Our analyses of developing Drosophila lacking H2Aub lead to the following main conclusions. First, monoubiquitylation of $\mathrm{H} 2 \mathrm{~A}$ and $\mathrm{H} 2 \mathrm{Av}$ is dispensable for repression of canonical PRCl targets such as the HOX genes or en. This suggests that nonenzymatic modification of chromatin (Shao et al. 1999; Francis et al. 2004) is the main mechanism by which PRC1 represses these genes. The requirement of Sce protein in canonical PRC1 may primarily reflect its architectural role in physically linking the H3-K27me3-binding activity of Pc (Fischle et al. 2003; Min et al.2003) to the chromatin-compacting activities of the Psc and Ph subunits (Francis et al. 2004). A second conclusion can be drawn from the reduction of bulk H3-K27me3 levels in embryos lacking H2Aub. On the one hand, this observation supports our earlier finding that $\mathrm{H} 2 \mathrm{Aub}$ promotes $\mathrm{H} 3-\mathrm{K} 27$ trimethylation by PRC 2 on nulceosomes in vitro (Kalb et al. 2014). On the other hand, the reduction of $\mathrm{H} 3-\mathrm{K} 27 \mathrm{me} 3$ is less than twofold, and, even though we do not know where 
it occurs in the genome, a drastic reduction at the HOX or en genes seems unlikely because high H3-K27me3 levels at these genes are critical for repression (Nekrasov et al. 2007; Pengelly et al. 2013). We conclude that at canonical PcG target genes, PRC2 generates sufficient levels of H3-K27me3 independently of H2Aub. A third point to discuss is the phenotype and the cause of lethality of animals lacking H2Aub. Sce $e^{I 48 A ~ m-z-}$ mutant embryos and $S c e^{I 48 A}$ - individuals that develop into pharate adults show remarkably subtle morphological defects that seem to occur stochastically in different locations of the body. Similarly, even though the H2A lysine residues monoubiquitylated by Sce are critical for organism viability, $H 2 A^{4 K>4 R}$ mutant cells can differentiate to form normal epidermal structures. Our transcriptome analyses in Sce $e^{I 48 \mathrm{~A} \mathrm{m-z-}}$ mutant embryos failed to identify genes that are significantly misregulated in these embryos (data not shown). It is possible that lethality in $\mathrm{H} 2 \mathrm{Aub}$-deficient animals is caused by a combination of multiple minor defects in regulating genes that control morphogenesis or, alternatively, a failure to regulate genes controlling changes in physiology or behavior at specific developmental time points. What these genes are and whether Sce E3 ligase activity regulates them as part of canonical PRC1 or another PRC1-type complex remain to be determined. Finally, we note that the requirement for H2Aub in developing Drosophila appears to be quite different from that in ES cells, where H2Aub was reported to be critical for repression of HOX and other PRC1 target genes and for maintenance of ES cell identity (Endoh et al. 2012). It will be interesting to investigate the requirement of H2Aub during mouse development and find out how the role of this modification evolved to contribute to PRC1mediated repression in higher metazoans.

\section{Materials and methods}

Drosophila strains and antibodies

Strain genotypes and antibodies used in this study are described in Supplemental Tables S1 and S2.

\section{Preparation of nuclear and chromatin extracts}

Soluble nuclear extracts from embryos were prepared as described (Scheuermann et al. 2010). For chromatin extracts, the pellet obtained after ultracentrifugation was solubilized in urea buffer ( $8 \mathrm{M}$ urea, $20 \mathrm{mM}$ Tris at $\mathrm{pH} 8,10 \mathrm{mM}$ DTT) and sonicated (Bioruptor).

For small-scale preparations of nuclei, the subcellular protein fractionation kit for tissues (Pierce) was used. Pelleted nuclei were resuspended in $2 \times$ LDS sample buffer (Invitrogen) and disrupted by sonication (Bioruptor).

\section{Acid extraction of histones}

Histones were acid-extracted from embryos or diploid larval imaginal disc and CNS tissues as described (Nekrasov et al. 2007).

\section{Generation of Sce $\mathrm{KO} \mathrm{m-z-}^{\mathrm{K} \text { embryos }}$}

The conditionally removable genomic Sce rescue construct $>S c e^{+}>$was based on a previously described vector (Gambetta and Müller 2014) that was modified to contain an attB site. The genomic Sce fragment comprised chr3R sequences 27680208-27683747 (Berkeley Drosophila Genome Project [BDGP] R6). The construct was integrated into the J27 (Bloomington Drosophila Stock Center [BDSC] 24482) attP landing site. One copy of the $>S c e^{+}>$transgene rescued $S c e^{K O}$ homozygotes into viable and fertile flies that were indistinguishable from wild type. $S c e^{K O ~ m-z-}$ and $S c e^{I 48 A \mathrm{~m}-z-}$ embryos were generated as described in Supplemental Figure
$\mathrm{S} 1$ and were identified by loss of the GFP reporter in the $>\mathrm{Sce}^{+}>$cassette. The $S c e^{I 48 A}$ transgene on chr2 (Supplemental Fig. S1) was integrated in attP site VK37 (BDSC 24872); it contained the same genomic Sce fragment but with an I48A point mutation and lacked FRT-LoxP and GFP elements. An $S c e^{+}$transgene in VK37, used as a control, fully rescued $S c e^{K O}$ homozygotes. Excision efficiency of the $>S c e^{+}>$cassette was $98 \%$, as previously reported for another cassette (Gambetta and Müller 2014). Plasmid maps are available on request.

\section{Generation of the $\mathrm{H} 2 \mathrm{Av}^{\mathrm{KO}}$ deletion allele}

Ends-out recombination was used to disrupt $H 2 A v$ and replace its entire coding region (BDGP R6 chr3R: 26,866,929-26,869,220) by mini-white using a previously described strategy (Gong and Golic 2003). Three-thousand-eight-hundred-twenty-one base pairs of $H 2 A v 5^{\prime}$ flanking sequences (BDGP R6 chr3R: 26,863,224-26,867,045) and 4881 bp of $3^{\prime}$ flanking sequences (BDGP R6 chr3R: 26,869,197-26,874,078) were cloned into pw35 (Gong and Golic 2003). Several independent targeting events that failed to complement the lethality of $H 2 A v^{810}$ were isolated. Successful disruption of $H 2 A v$ was confirmed by PCR analysis with primers pairs (5' to $\left.3^{\prime}\right)$ GACCTTGGAGCGACTGTC and CACCAAACTTCAAC TACTG, ACTCGTGCTGACGACCTGAAC and CACATTGTTCAGAT GCTCGG, and GCGCAGGTAGAAGTGCATC and CACGGCTGCAGT GGCTC (Supplemental Fig. S5). The $H 2 A v$ rescue transgene $H 2 A v{ }^{W T}$ contained $H 2 A v$ coding and flanking sequences (BDGP R6 chr3R: 26,866,577$26,869,660$ ) in a modified attB vector and was integrated into the VK37 attP site. The same strategy was used to generate animals carrying the $H 2 A v^{2 K>2 R}$ transgene.

\section{Generation of histone transgenes}

Site-directed mutagenesis on pENTR221-HisGU.WT, pENTRL4R1HisGU.WT, and pENTRR2L3-HisGU.WT (Günesdogan et al. 2010) was used to mutate histone H2A specifically at Lys117, Lys118, Lys121, and Lys122 into arginines. The final construct pfC31-attB-3xHisGU.H2AK117R/K118R/K121R/K122R, generated by Gateway LR recombination of the above vectors, was integrated at attP sites VK33 (BDSC 9750) and 86Fb (BDSC 130437).

\section{Immunostaining and cuticle preparations of Drosophila}

Immunostaining of embryos and imaginal discs and generation of clones in discs and adults were performed following standard protocols.

\section{H2A ubiquitylation assays}

In vitro ubiquitylation of reconstituted recombinant Drosophila mononucleosomes were performed as described (Kalb et al. 2014).

\section{Acknowledgments}

We thank Dale Dorsett for discussions, and Robert Glaser for providing anti-H2Av antibody. This work was supported by the Marie Curie Initial Training Network Nucleosome4D, the European Commission Seventh Framework Program 4DCellFate (grant no. 277899), the Deutsche Forschungsgemeinschaft (SFB1064), and the Max-Planck Society.

\section{References}

Beisel C, Paro R. 2011. Silencing chromatin: comparing modes and mechanisms. Nat Rev Genet 12: 123-135.

Bentley ML, Corn JE, Dong KC, Phung Q, Cheung TK, Cochran AG. 2011. Recognition of UbcH5c and the nucleosome by the Bmil/Ring1b ubiquitin ligase complex. EMBO J 30: 3285-3297.

Blackledge NP, Farcas AM, Kondo T, King HW, McGouran JF, Hanssen LLP, Ito S, Cooper S, Kondo K, Koseki Y, et al. 2014. Variant PRC1 complex-dependent H2A ubiquitylation drives PRC2 recruitment and polycomb domain formation. Cell 157: 1445-1459.

Buchwald G, van der Stoop P, Weichenrieder O, Perrakis A, van Lohuizen M, Sixma TK. 2006. Structure and E3-ligase activity of the Ring-Ring complex of polycomb proteins Bmil and Ring1b. EMBO $J$ 25: 2465-2474. 
de Napoles M, Mermoud JE, Wakao R, Tang YA, Endoh M, Appanah R, Nesterova TB, Silva J, Otte AP, Vidal M, et al. 2004. Polycomb group proteins Ring1A/B link ubiquitylation of histone H2A to heritable gene silencing and X inactivation. Dev Cell 7: 663-676.

Elderkin S, Maertens GN, Endoh M, Mallery DL, Morrice N, Koseki H, Peters G, Brockdorff N, Hiom K. 2007. A phosphorylated form of Mel-18 targets the Ring1B histone H2A ubiquitin ligase to chromatin. Mol Cell 28: 107-120.

Endoh M, Endo TA, Endoh T, Isono K-I, Sharif J, Ohara O, Toyoda T, Ito T, Eskeland R, Bickmore WA, et al. 2012. Histone H2A mono-ubiquitination is a crucial step to mediate PRC1-dependent repression of developmental genes to maintain ES cell identity. PLoS Genet 8: e1002774.

Eskeland R, Leeb M, Grimes GR, Kress C, Boyle S, Sproul D, Gilbert N, Fan Y, Skoultchi AI, Wutz A, et al. 2010. Ring1B compacts chromatin structure and represses gene expression independent of histone ubiquitination. Mol Cell 38: 452-464.

Fischle W, Wang Y, Jacobs SA, Kim Y, Allis CD, Khorasanizadeh S. 2003. Molecular basis for the discrimination of repressive methyl-lysine marks in histone H3 by Polycomb and HP1 chromodomains. Genes Dev 17: 1870-1881.

Francis NJ, Kingston RE, Woodcock CL. 2004. Chromatin compaction by a polycomb group protein complex. Science 306: 1574-1577.

Gambetta MC, Müller J. 2014. O-GlcNacylation prevents aggregation of the polycomb group repressor polyhomeotic. Dev Cell 31: 629-639.

Gao Z, Zhang J, Bonasio R, Strino F, Sawai A, Parisi F, Kluger Y, Reinberg D. 2012. PCGF homologs, CBX proteins, and RYBP define functionally distinct PRC1 family complexes. Mol Cell 45: 344-356.

Gong WJ, Golic KG. 2003. Ends-out, or replacement, gene targeting in Drosophila. Proc Natl Acad Sci 100: 2556-2561.

Günesdogan U, Jäckle H, Herzig A. 2010. A genetic system to assess in vivo the functions of histones and histone modifications in higher eukaryotes. EMBO Rep 11: 772-776.

Gutiérrez L, Oktaba K, Scheuermann JC, Gambetta MC, Ly-Hartig N, Müller J. 2012. The role of the histone H2A ubiquitinase Sce in Polycomb repression. Development 139: 117-127.

Isono K, Endo TA, Ku M, Yamada D, Suzuki R, Sharif J, Ishikura T, Toyoda T, Bernstein BE, Koseki H. 2013. SAM domain polymerization links subnuclear clustering of PRC1 to gene silencing. Dev Cell 26:565-577.

Kalb R, Latwiel S, Baymaz HI, Jansen PWTC, Müller CW, Vermeulen M, Müller J. 2014. Histone H2A monoubiquitination promotes histone H3 methylation in Polycomb repression. Nat Struct Mol Biol 21: 569-571.

King IFG, Emmons RB, Francis NJ, Wild B, Müller J, Kingston RE, Wu C-T. 2005. Analysis of a polycomb group protein defines regions that link repressive activity on nucleosomal templates to in vivo function. Mol Cell Biol 25: 6578-6591.

Lagarou A, Mohd-Sarip A, Moshkin YM, Chalkley GE, Bezstarosti K, Demmers JAA, Verrijzer CP. 2008. dKDM2 couples histone H2A ubiquitylation to histone $\mathrm{H} 3$ demethylation during Polycomb group silencing. Genes Dev 22: 2799-2810.
Leeb M, Wutz A. 2007. Ring1B is crucial for the regulation of developmental control genes and PRCl proteins but not X inactivation in embryonic cells. J Cell Biol 178: 219-229.

Li Z, Cao R, Wang M, Myers MP, Zhang Y, Xu R-M. 2006. Structure of a Bmi-1-Ring1B polycomb group ubiquitin ligase complex. I Biol Chem 281: 20643-20649.

McGinty RK, Henrici RC, Tan S. 2014. Crystal structure of the PRC1 ubiquitylation module bound to the nucleosome. Nature 514: 591-596.

McKay DJ, Klusza S, Penke TJR, Meers MP, Curry KP, McDaniel SL, Malek PY, Cooper SW, Tatomer DC, Lieb JD, et al. 2015. Interrogating the function of metazoan histones using engineered gene clusters. Dev Cell 32: 373-386.

Min J, Zhang Y, Xu R-M. 2003. Structural basis for specific binding of Polycomb chromodomain to histone H3 methylated at Lys 27. Genes Dev 17: 1823-1828.

Nekrasov M, Klymenko T, Fraterman S, Papp B, Oktaba K, Köcher T, Cohen A, Stunnenberg H, Wilm M, Müller J. 2007. Pcl-PRC2 is needed to generate high levels of H3-K27 tri-methylation at Polycomb target genes. EMBO I 26: 4078-4088.

Pengelly AR, Copur Ö, Jäckle H, Herzig A, Müller J. 2013. A histone mutant reproduces the phenotype caused by loss of histone-modifying factor Polycomb. Science 339: 698-699.

Scheuermann JC, de Ayala Alonso AG, Oktaba K, Ly-Hartig N, McGinty RK, Fraterman S, Wilm M, Muir TW, Müller J. 2010. Histone H2A deubiquitinase activity of the Polycomb repressive complex PR-DUB. Nature 465: 243-247.

Schoorlemmer J, Marcos-Gutiérrez C, Were F, Martínez R, García E, Satijn DPE, Otte AP, Vidal M. 1997. Ring1 A is a transcriptional repressor that interacts with the Polycomb-M33 protein and is expressed at rhombomere boundaries in the mouse hindbrain. EMBO J 16: 5930-5942.

Shao Z, Raible F, Mollaaghababa R, Guyon JR, Wu CT, Bender W, Kingston RE. 1999. Stabilization of chromatin structure by PRC1, a Polycomb complex. Cell 98: 37-46.

Simon JA, Kingston RE. 2013. Occupying chromatin: Polycomb mechanisms for getting to genomic targets, stopping transcriptional traffic, and staying put. Mol Cell 49: 808-824.

Stock JK, Giadrossi S, Casanova M, Brookes E, Vidal M, Koseki H, Brockdorff N, Fisher AG, Pombo A. 2007. Ring1-mediated ubiquitination of $\mathrm{H} 2 \mathrm{~A}$ restrains poised RNA polymerase II at bivalent genes in mouse ES cells. Nat Cell Biol 9: 1428-1435.

Voncken JW, Roelen BAJ, Roefs M, de Vries S, Verhoeven E, Marino S, Deschamps J, van Lohuizen M. 2003. Rnf2 (Ring1b) deficiency causes gastrulation arrest and cell cycle inhibition. Proc Natl Acad Sci 100: $2468-2473$.

Wang H, Wang L, Erdjument-Bromage H, Vidal M, Tempst P, Jones RS, Zhang Y. 2004. Role of histone H2A ubiquitination in Polycomb silencing. Nature 431: 873-878.

Wang R, Taylor AB, Leal BZ, Chadwell LV, Ilangovan $\mathrm{U}$, Robinson $\mathrm{AK}$, Schirf V, Hart PJ, Lafer EM, Demeler B, et al. 2010. Polycomb group targeting through different binding partners of RING1B C-terminal domain. Structure 18: 966-975. 


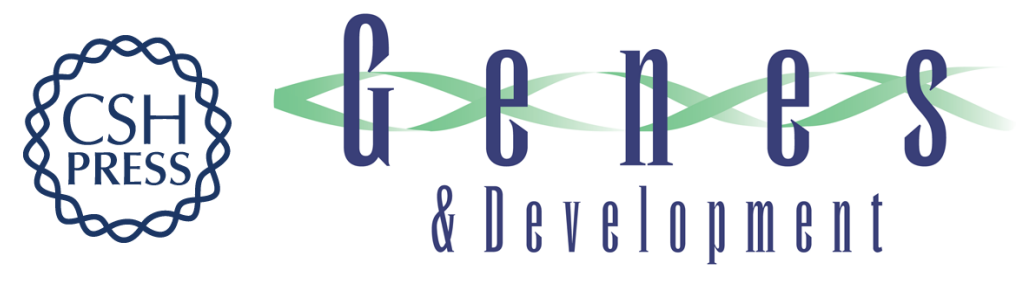

\section{Transcriptional repression by PRC1 in the absence of H2A monoubiquitylation}

Ana Raquel Pengelly, Reinhard Kalb, Katja Finkl, et al.

Genes Dev. 2015, 29: originally published online July 15, 2015

Access the most recent version at doi:10.1101/gad.265439.115

\section{Supplemental http://genesdev.cshlp.org/content/suppl/2015/07/13/gad.265439.115.DC1 \\ Material}

References This article cites 34 articles, 16 of which can be accessed free at:

http://genesdev.cshlp.org/content/29/14/1487.full.html\#ref-list-1

Creative This article is distributed exclusively by Cold Spring Harbor Laboratory Press for the first

Commons six months after the full-issue publication date (see

License http://genesdev.cshlp.org/site/misc/terms.xhtml). After six months, it is available under a Creative Commons License (Attribution-NonCommercial 4.0 International), as described at http://creativecommons.org/licenses/by-nc/4.0/.

Email Alerting Receive free email alerts when new articles cite this article - sign up in the box at the top Service right corner of the article or click here.

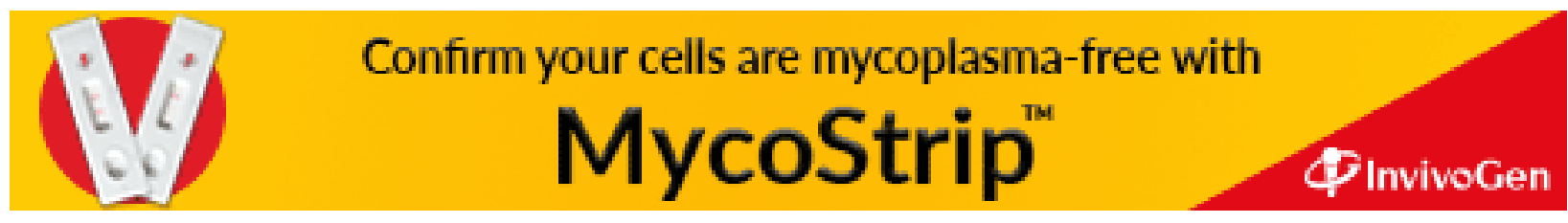

